\title{
Protection of rusted reinforcing steel in concrete by IFKhAN-85 inhibitor
}

\author{
I.A. Gedvillo, A.S. Zhmakina, N.N. Andreev* and S.S. Vesely \\ A.N. Frumkin Institute of Physical Chemistry and Electrochemistry, Russian Academy of \\ Sciences, Leninsky pr. 31, 119071 Moscow, Russian Federation \\ *E-mail: n.andreev@mail.ru
}

\begin{abstract}
In inhibitory protection of reinforced concrete structures, one often has to deal with rusted reinforcing steel. Therefore, studies on the effect of corrosion inhibitors (contact and migrating ones) on the corrosion-electrochemical behavior of rusted reinforcing steel in concrete is a mandatory stage in the development of efficient anticorrosion formulations. It was previously shown in experiments on stripped reinforcing steel that some phenol derivatives effectively prevented corrosion initiation in simulated chloride-containing pore fluid. In this work, we studied the protective properties of catechol (IFKhAN-85) toward rusted reinforcing steel in concrete. Using corrosion-electrochemical methods, it was shown that incorporation of $1 \%$ IFKhAN-85 with tempering water into concrete containing 3\% $\mathrm{NaCl}$ provides a passive state of rusted reinforcing steel under severe conditions of moisture capillary suction and permanent anodic polarization. External treatment of the concrete surface of samples made using rusted reinforcing wire with $3 \%$ IFKhAN-85 solution converts steel to the passive state.
\end{abstract}

Keywords: corrosion in concrete, corrosion inhibitors, contact corrosion inhibitors, migrating corrosion inhibitors, pyrocatechol.

Received: April 1, 2020. Published: April 28, 2020

doi: $\underline{10.17675 / 2305-6894-2020-9-2-11}$

\section{Introduction}

Corrosion of reinforcing steel is a common reason of the destruction of reinforced concrete structures [1]. The use of inhibitors is an efficient method to suppress this kind of damage [2]. They can be introduced into concrete with tempering water (contact inhibitors) or applied to the surface of concrete (migrating inhibitors). Calcium or sodium nitrites are most commonly used for the protection of reinforced concrete structures [2]. It is generally accepted that they have no competitors in efficiency among individual compounds. Nevertheless, it was shown [3-5] that some phenol derivatives could exceed their protective efficiency in simulated chloride-containing pore fluid. On steel samples cleaned from rust, hydroquinone and pyrocatechol (IFKhAN-85) provided complete protection of steel at concentrations several times lower than sodium nitrite [5].

However, in practice, one often has to deal with rusted reinforcing steel. It has to be admitted that only in some cases, products of atmospheric corrosion are removed from 
reinforcing steel or converted before pouring concrete. Therefore, ideally, contact inhibitors should provide protection not only for a metal freed from rust but also for a rusted metal.

The ability to protect rusted reinforcing steel is even more important for migrating inhibitors. As a rule, when their application begins, there are already significant areas of corrosion on reinforcing steel.

In view of this, the purpose of this work was to study the protective properties of IFKhAN-85 toward rusted reinforcing steel in concrete.

\section{Experimental}

To study the protective ability of IFHAN-85, cylindrical concrete samples with St3ps steel cores were prepared. Pieces of reinforcement wire with a diameter of $6.5 \mathrm{~mm}$ and a length of $50 \mathrm{~mm}$ were cleaned with sandpaper, degreased with ethanol, and placed for 2 years in a desiccator with a volume of 5 liters. Distilled water $(100 \mathrm{ml})$ was placed on the bottom of the desiccator. Steel underwent general corrosion under these conditions. At the end of exposure, a continuous layer of rust formed on the wires.

The rusted wire pieces were removed from the desiccator, dried in air and placed vertically along the axis of cylindrical casings with a diameter of $40 \mathrm{~mm}$ and a height of $50 \mathrm{~mm}$. The casings were filled with a concrete mass (Portland cement PTs 500 D0, sand sifted through a sieve with a mesh of $2 \mathrm{~mm}$, and water, at a component ratio of 1:2:0.4, respectively) so that an upper part $(5 \mathrm{~mm})$ of each reinforcing wire piece protruded from concrete. $\mathrm{NaCl}$ was added to concrete with tempering water (3\% of the cement mass). In studies on the inhibitor ability for contact protection, IFKhAN-85 (0.75 or $1.0 \%$ of the cement mass) was also added.

After concrete hardening (10 days), samples were removed from the casings and, in studies on the properties of IFKhAN-85 as a migrating inhibitor, dipped for 1 minute into its $3 \%$ aqueous solution or into pure water.

After another 5 days, the samples were placed in Petri dishes filled with water by 2-4 mm with their butt ends that did not have a reinforcing wire part outside. The samples were kept for 2 months under capillary moisture suction conditions. During that period, the potentials of steel were measured and occasionally (on the 10th and 60th days of exposure) polarization curves were recorded.

A PI-50-1 potentiostat was used to record the polarization curves. A stainless steel plate was used as the auxiliary electrode. The potentials of steel were measured against a saturated silver/silver chloride reference electrode and then converted to the normal hydrogen scale. Reinforcing steel was polarized stepwise by shifting the potential from the stationary value by $0.1 \mathrm{~V}$ every minute, first in the cathodic direction (to $-0.8 \mathrm{~V}$ ) and then in the anodic direction (to $+1.2 \mathrm{~V}$ ). The currents were measured immediately before switching the potential.

After exposure of the samples for 2 months in Petri dishes, steel was anodically polarized from a battery $(1.25 \mathrm{~V})$. A stainless steel plate was used as the auxiliary electrode. 
The polarization was maintained for another 2 months, while periodically recording the currents in the "reinforcing wire-auxiliary electrode" circuit.

\section{Results and discussion}

Protective ability of IFKhAN-85 toward rusted reinforcing steel when it is added to concrete with tempering water

If IFKhAN-85 is not present in concrete, the potentials of steel ennobled with time during exposure of samples under capillary moisture suction conditions (Figure 1). While they ranged from -0.15 to $-0.3 \mathrm{~V}$ at the beginning of the experiment, their variation range between measurements was from 0.0 to $+0.15 \mathrm{~V}$ after $50-60$ days.

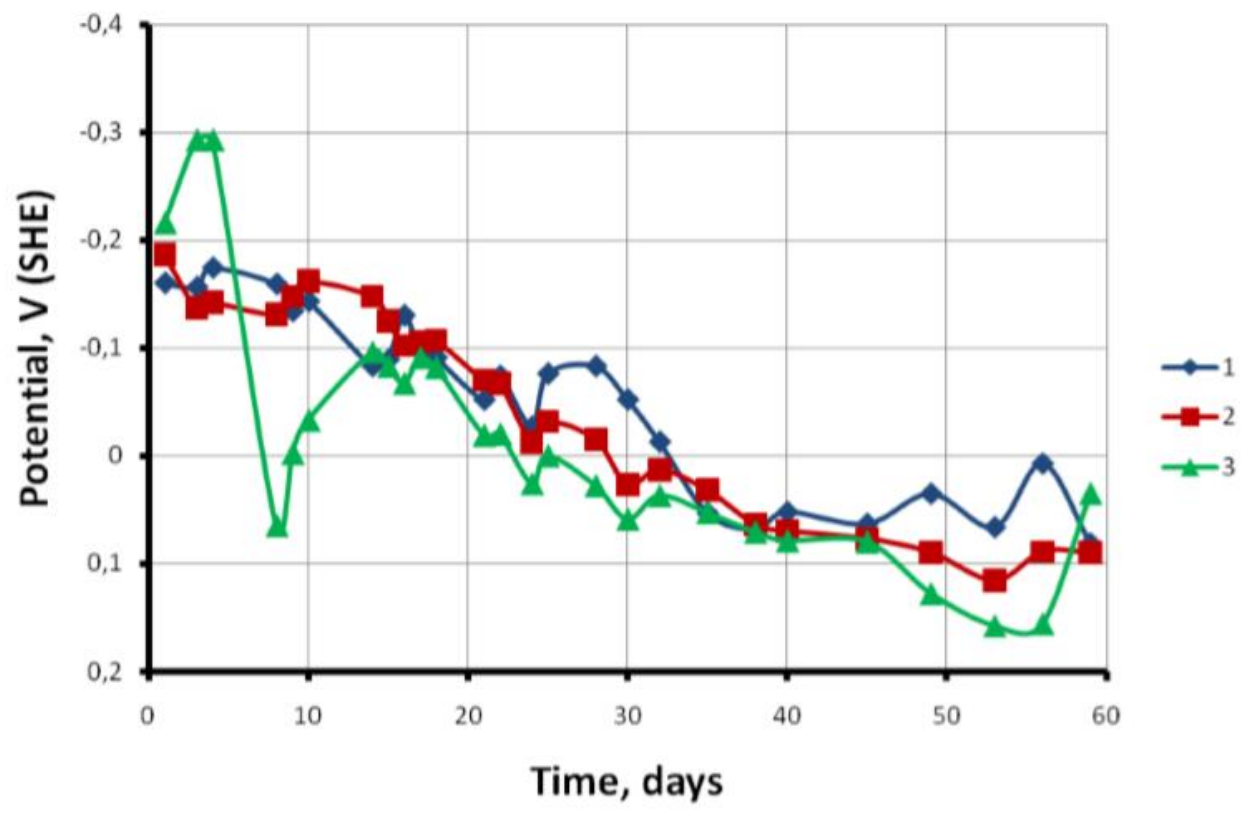

Figure 1. Chronopotentiometric curves of rusted reinforcing steel in concrete containing 3\% $\mathrm{NaCl}$ and inhibitor additives. 1 - without IFKhAN-85; 2 - 0.75\% IFKhAN-85; $3-1.0 \%$

IFKhAN-85. Moisture capillary suction conditions.

Addition of IFKhAN-85 to concrete with tempering water did not change the overall pattern. Regardless of its content, the potential values shifted in the positive direction with time. This indicates that the anodic process gradually slows down and the samples are passivated under the conditions of this experiment. However, the differences between the potential-time plots obtained for concrete with various inhibitor amounts and without it did not exceed the data scatter between parallel experiments.

This does not allow one to make an unambiguous conclusion about the ability of IFKhAN-85 to provide contact protection of steel in concrete. Apparently, under the conditions under consideration, which are rather mild from the corrosion point of view, steel is passivated, regardless of the presence of IFKhAN-85 in concrete, due to the alkalinity of the pore fluid. 
More severe conditions are created after recording the cathodic branches of polarization curves. Regardless of the presence or absence of IFKhAN-85 in concrete and the time of exposure with capillary suction, shifting the sample potential by less than $0.2 \mathrm{~V}$ brings about a sharp increase in the cathodic current due to reduction of the passive film on steel and oxygen dissolved in the pore liquid (Figures 2 and 3).

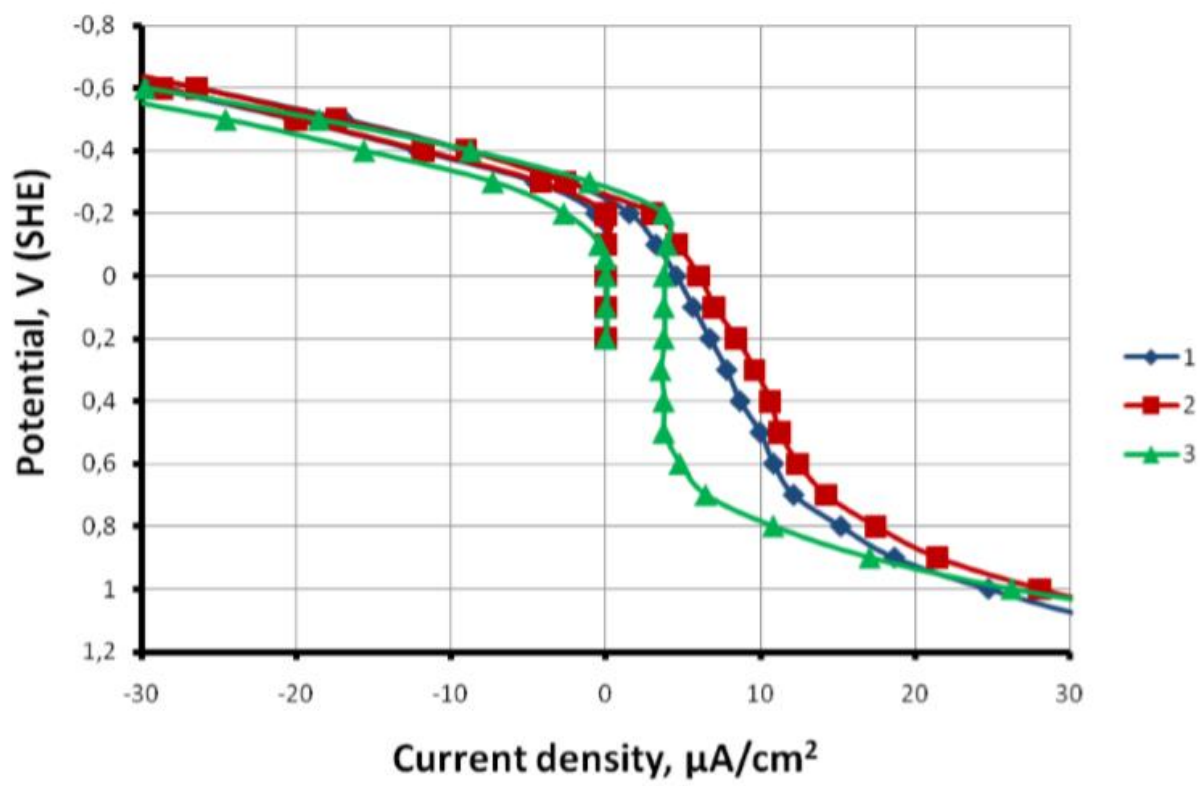

Figure 2. Polarization curves of rusted reinforcing steel in concrete containing $3 \% \mathrm{NaCl}$ and inhibitor additives. 1 - without IFKhAN-85; 2 - 0.75\% IFKhAN-85; 3 - 1.0\% IFKhAN-85. Time of exposure under conditions of capillary suction of moisture, 10 days.

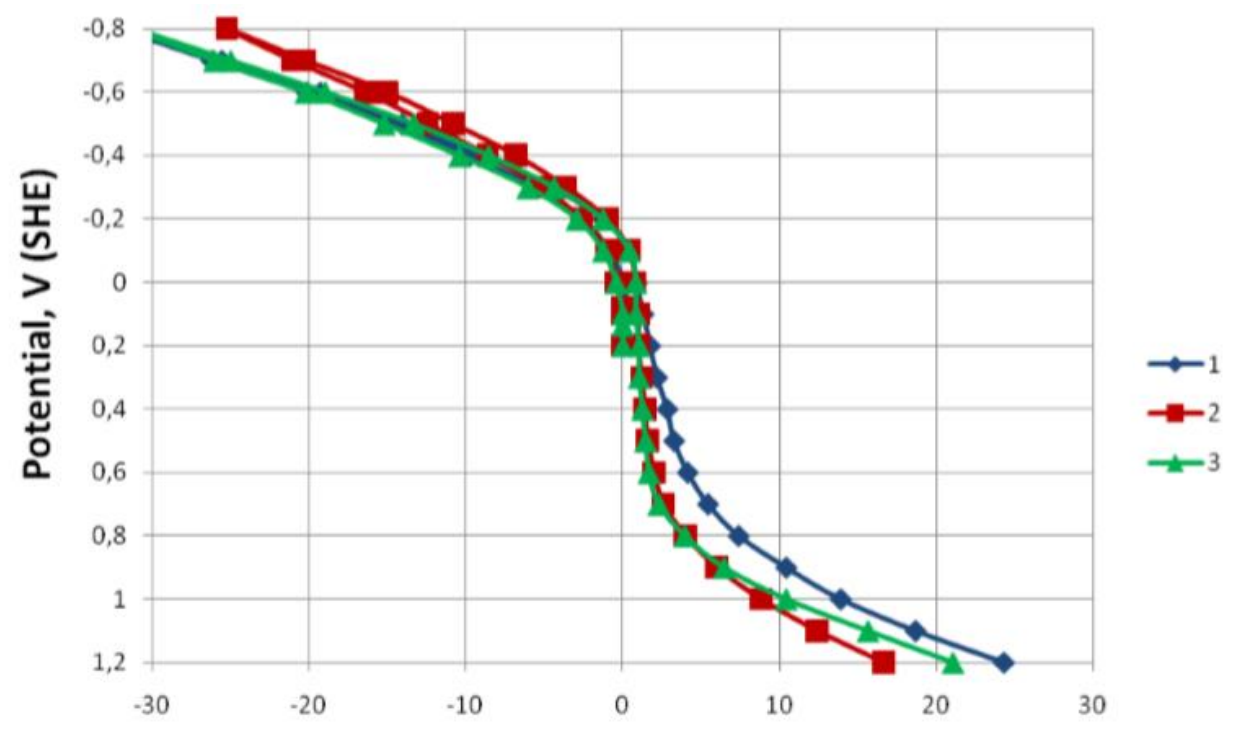

Current density, $\mu \mathrm{A} / \mathrm{cm}^{2}$

Figure 3. Polarization curves of rusted reinforcing steel in concrete containing $3 \% \mathrm{NaCl}$ and inhibitor additives. 1 - without IFKhAN-85; 2 - 0.75\% IFKhAN-85; 3 - 1.0\% IFKhAN-85. Time of exposure under conditions of capillary suction of moisture, 60 days. 
Changing the potential scan direction for a sample containing no IFKhAN-85 first results in a decrease in the cathodic current, and then (at potentials higher than $0.3 \mathrm{~V}$ ) to an increase in the anodic current.

For polarization curves recorded on the 10th day (Figure 2), the anodic current for samples containing no IFKhAN-85 increased almost linearly with an increase in potential. The linear section ended at $0.7-0.8 \mathrm{~V}$. It was followed by a section with a sharp current increase apparently associated with oxygen evolution.

Incorporation of $0.75 \%$ IFKhAN-85 into concrete nearly did not affect the anodic dissolution of steel. In this case, the polarization curves almost coincided with the curves obtained in the absence of the inhibitor. Addition of 1\% IFKhAN-85 changed the course of the curves. On the voltammetric plots, a passivity section appeared (from -0.2 to $+0.6 \mathrm{~V}$ ) where the anodic current density $\left(4-5 \mu \mathrm{A} / \mathrm{cm}^{2}\right)$ was considerably lower than in the absence of IFKhAN-85.

The exposure time of samples in Petri dishes with water had almost no effect on the cathodic branches of the polarization curves (Figure 3). Conversely, the anodic polarization curves changed strongly. The background curve after 60 days of exposure of samples under capillary suction conditions contained a region of passivity. The anodic current density in the range from -0.1 to $+0.5 \mathrm{~V}$ did not exceed $3 \mu \mathrm{A} / \mathrm{cm}^{2}$. IFKhAN- 85 markedly improved the passive state of steel. Its addition reduced the anodic current density 1.5-2 fold relative to the background curve.

The inhibitory effect of IFKhAN-85 becomes even more noticeable in experiments where steel is polarized anodically from a battery. These experiments simulate the effect of stray currents on reinforced concrete structures.

Addition of IFKhAN-85 favors the preservation of the passive state of reinforcing steel under these conditions, too. This is clearly seen on the plots of current density versus polarization time (Figure 4).

In the absence of IFKhAN-85, connection of a battery to the samples increased the current in the "reinforcing wire-auxiliary electrode" circuit. By the 5th day of polarization, the current density of steel dissolution increased to $6 \mu \mathrm{A} / \mathrm{cm}^{2}$. Further exposure of the samples under a voltage led to current fluctuations, but its value did not fall below $5 \mu \mathrm{A} / \mathrm{cm}^{2}$. The maximum current was recorded on days $30-35$ of the experiment. Its value reached $13 \mu \mathrm{A} / \mathrm{cm}^{2}$.

Incorporation of $0.75 \%$ IFKhAN-85 into concrete practically did not affect the anodic dissolution currents of steel. Their maximum values did not exceed $4 \mu \mathrm{A} / \mathrm{cm}^{2}$. Addition of $1 \%$ IFKhAN-85 inhibited the anodic dissolution even more noticeably. Starting from the 4th day of polarization, the current density in the circuit did not exceed $1 \mu \mathrm{A} / \mathrm{cm}^{2}$ in this case. It is significant that the first $1-4$ days of polarization of samples containing IFKhAN-85 were characterized by a peak increase in current. Steel passivation only occurred on the $5-7$ th day of polarization. It can be assumed that such an increase in current in the initial period is due to the formation of protective films on the steel surface. 
Thus, IFKhAN-85 added to concrete with tempering water provides efficient protection of rusted reinforcing steel.

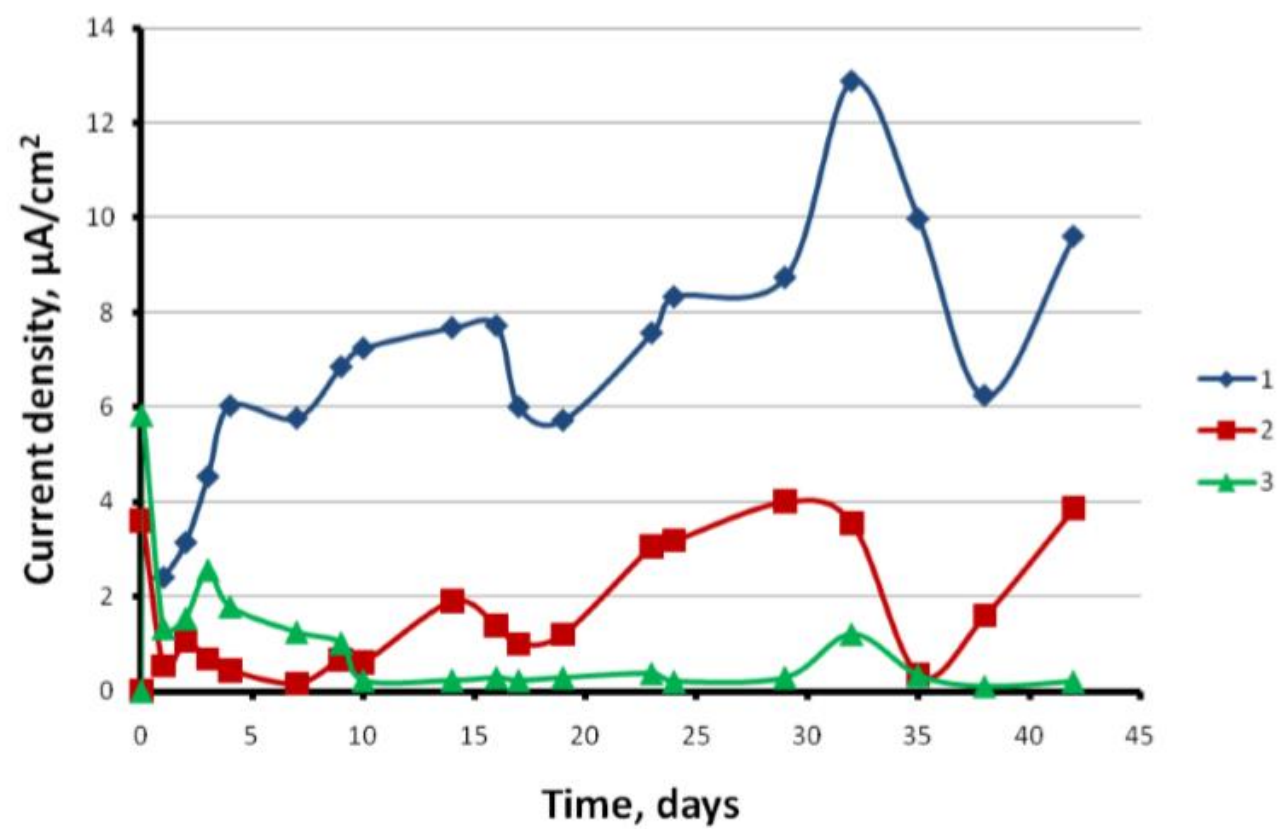

Figure 4. Chronoamperometric curves of rusted reinforcing steel in concrete containing $3 \%$ $\mathrm{NaCl}$ and inhibitor additives. 1 - without IFKhAN-85; $2-0.75 \%$ IFKhAN-85; $3-1.0 \%$ IFKhAN-85. Moisture capillary suction conditions. Anodic polarization from a battery.

The protective ability of IFKhAN-85 upon application of its solution onto concrete surface

The time variation in the reinforcing steel potential in concrete samples whose surfaces were treated with 3\% aqueous solution of IFKhAN-85 and which were then placed in Petri dishes is similar to the potential variation of samples treated with water (Figure 5). In both cases, the potential values increased from $-0.17 \ldots-0.15 \mathrm{~V}$ to approximately $-0.1 \mathrm{~V}$.

The polarization curves recorded on the 10th and 60th days were also close for both surface treatment techniques (Figures 6 and 7). It should be noted that increasing the time of exposure of samples under water capillary suction conditions led to steel passivation by itself. The efficiency of IFKhAN-85 as a migrating inhibitor was difficult to estimate against the background of this process.

Testing under more severe conditions with a battery connected to the samples unambiguously indicates the high efficiency of IFKhAN-85 as a migrating corrosion inhibitor. The dissolution currents of steel in the samples treated with water increased with time. The maximum anodic current density was recorded on the 33rd day of polarization and amounted to $13 \mu \mathrm{A} / \mathrm{cm}^{2}$. In the case of concrete surface treatment with IFKhAN-85 solution, the current density nearly did not change with time and, starting from the 15 th day of the experiment, did not exceed $0.5 \mu \mathrm{A} / \mathrm{cm}^{2}$ (Figure 8). 


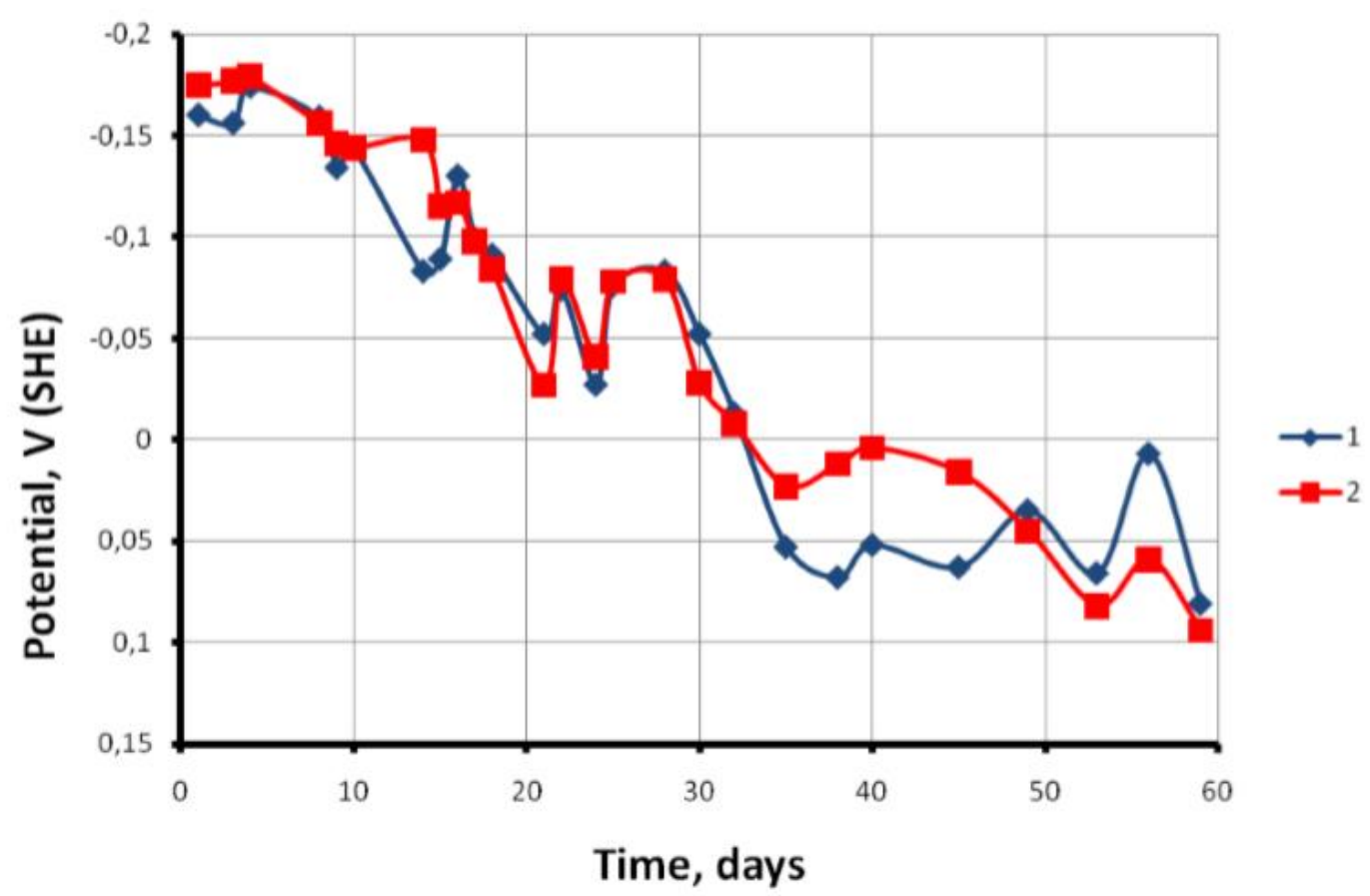

Figure 5. Chronopotentiometric curves of rusted reinforcing steel in concrete containing 3\% $\mathrm{NaCl}$. Samples treatment on the outside: 1 - water; 2 - 3\% aqueous solution of IFKhAN-85. Moisture capillary suction conditions.

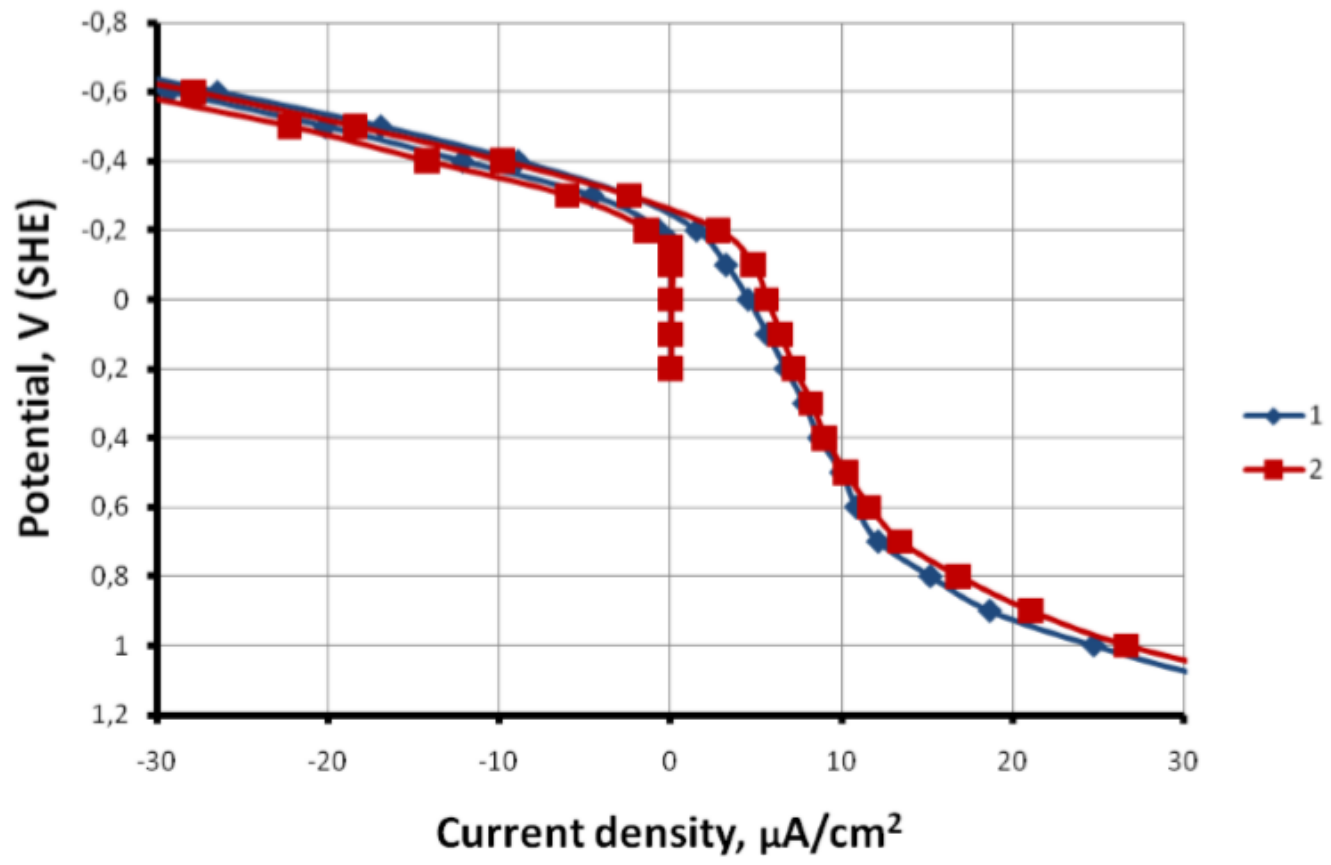

Figure 6. Polarization curves of rusted reinforcing steel in concrete containing $3 \% \mathrm{NaCl}$. Samples treatment on the outside: 1 - water; 2 - 3\% aqueous solution of IFKhAN-85. Time of exposure under conditions of capillary suction of moisture: 10 days. 


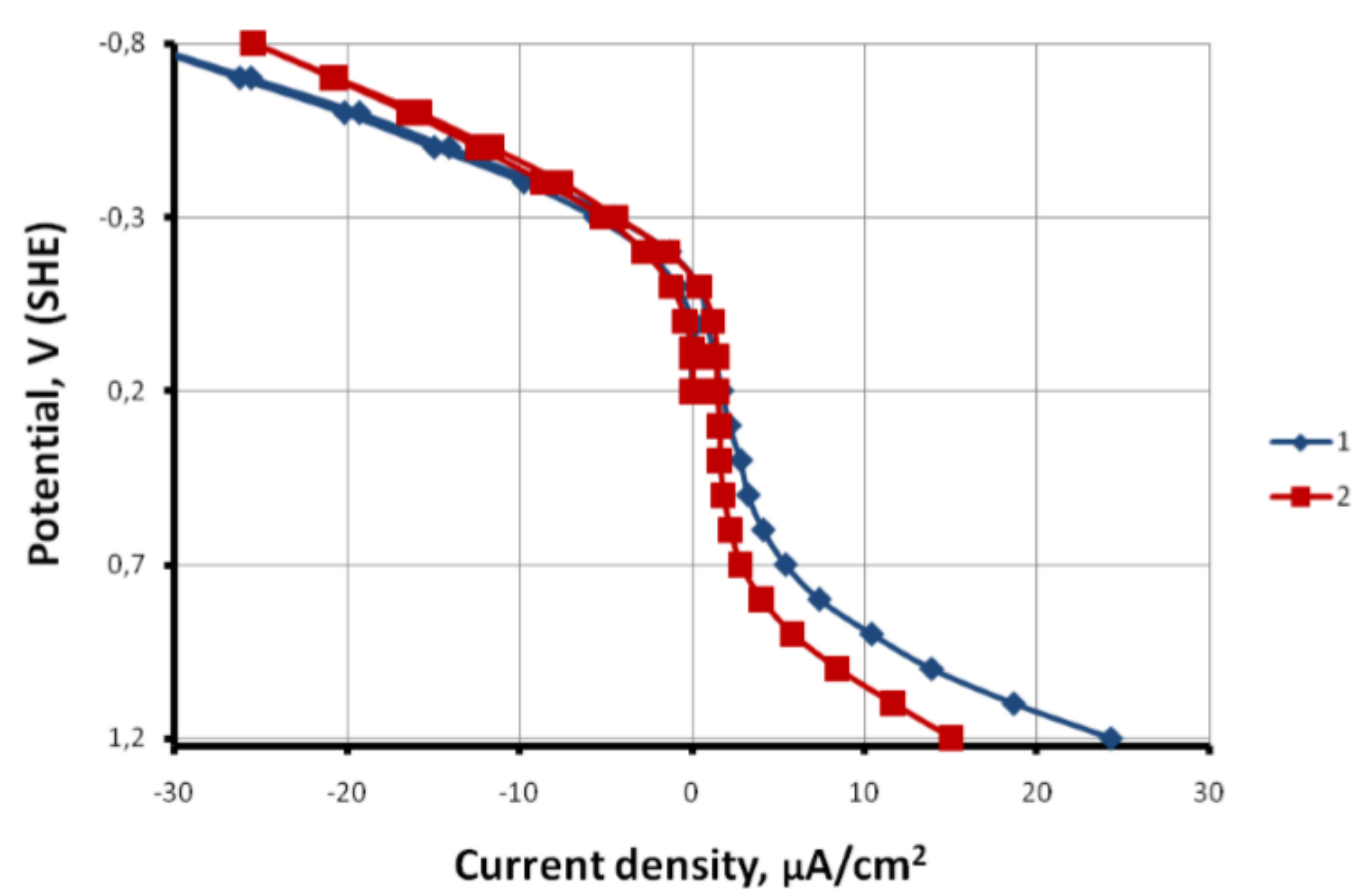

Figure 7. Polarization curves of rusted reinforcing steel in concrete containing $3 \% \mathrm{NaCl}$. Samples treatment on the outside: 1 - water; 2 - 3\% aqueous solution of IFKhAN-85. Time of exposure under conditions of capillary suction of moisture: 60 days.

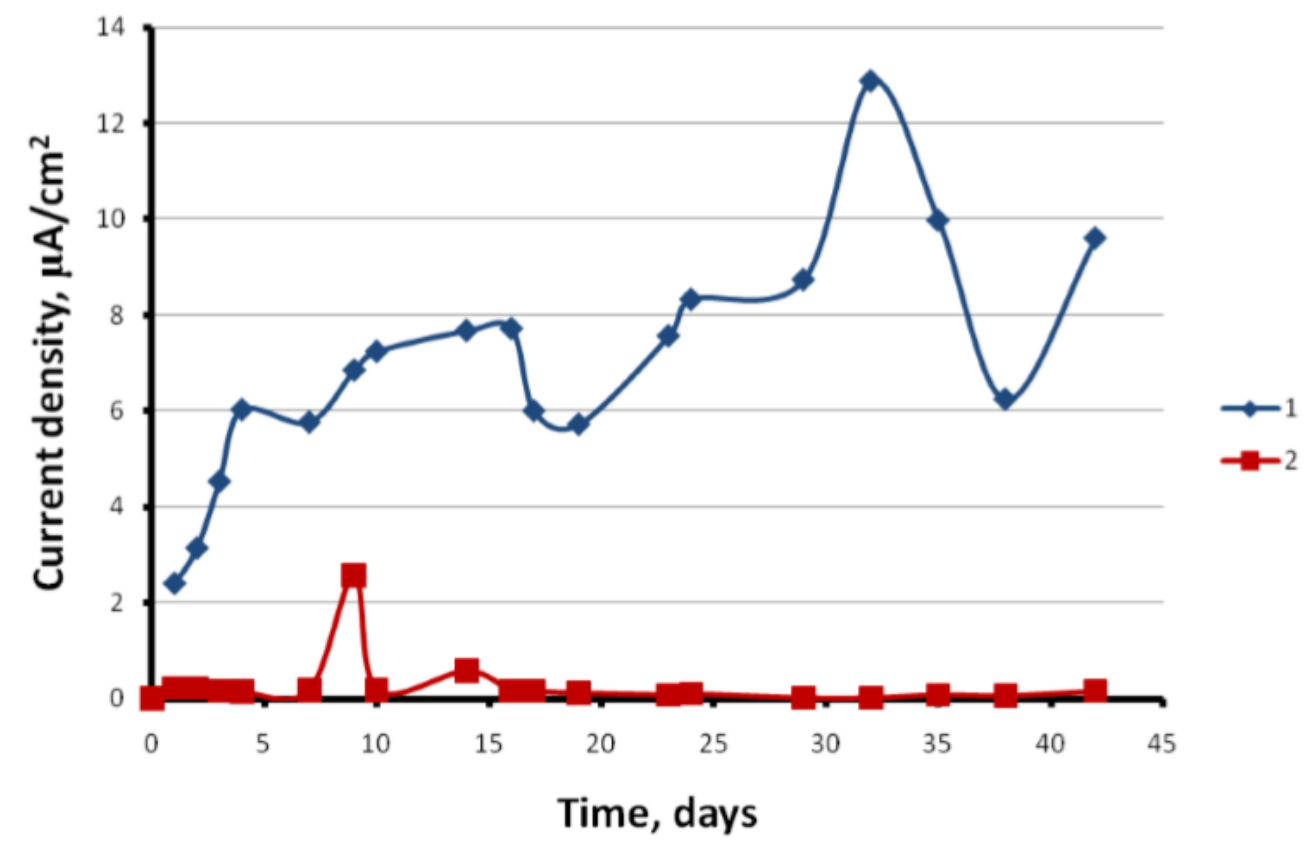

Figure 8. Chronoamperometric curves of rusted reinforcing steel in concrete containing $3 \%$ $\mathrm{NaCl}$. Samples treatment on the outside: 1 - water; $2-3 \%$ aqueous solution of IFKhAN-85. Moisture capillary suction conditions. Anodic polarization from a battery. 


\section{Conclusions}

1. Using corrosion-electrochemical methods, it has been shown that addition of $1 \%$ IFKhAN-85 with tempering water into concrete containing $3 \% \mathrm{NaCl}$ ensures a passive state of rusted reinforcing steel under severe conditions of moisture capillary suction and permanent anodic polarization.

2. External treatment of the concrete surfaces of samples made using rusted reinforcing wire with $3 \%$ IFKhAN-85 solution transfers steel to the passive state.

\section{References}

1. S.N. Alekseev, Korroziya i zashchita armatury v betone (Corrosion and protection of reinforcing steel in concrete), Moscow, Izd. literatury po stroitel'stvu (Building literature publishing), 1968, 231 pp. (in Russian).

2. S.N. Alekseev, V.B. Ratinov, N.K. Rozental' and N.M. Kashurnikov, Ingibitory korrozii stali $v$ zhelezobetonnykh konstruktsiyakh (Corrosion inhibitors of steel in reinforcing steel structures), Moscow, Stroiizdat, 1985, 272 pp. (in Russian).

3. I.A. Gedvillo, A.S. Zhmakina and N.N. Andreev, Ingibirovanie korrozii stali v model'noi porovoi zhidkosti betona proizvodnymi fenola (Steel corrosion inhibition in simulated concrete porous fluids by phenol derivatives), Prakt. Protivokorroz. Zashch., 2019, 24, no. 4, 15-19 (in Russian).

4. I.A. Gedvillo, A.S. Zhmakina, N.N. Andreev and S.S. Vesely, Effect of hydroquinone and pyrocatechin on the corrosion and electrochemical behavior of steel in simulated concrete pore liquid, Int. J. Corros. Scale Inhib., 2019, 8, no. 3, 560-572. doi: 10.17675/2305-6894-2019-8-3-7

5. I.A. Gedvillo, A.S. Zhmakina and N.N. Andreev, Sravnenie zashchitnykh svoistv nitrita natriya, gidrokhinona I pirokatekhina $\mathrm{v}$ model'noi porovoi zhidkosti betona (Comparison of protective properties of sodium nitrite, hydroquinone and pyrocatechol in simulated concrete pour liquid), Korroz.: mater., zashch. (Corrosion: materials, protection), 2019, no. 11, 19-25 (in Russian). 